\title{
Comparison between chironomid-inferred July temperatures and meteorological data AD 1850-2001 from varved Lake Silvaplana, Switzerland
}

\author{
Isabelle Larocque • Martin Grosjean • \\ Oliver Heiri · Christian Bigler · Alex Blass
}

Received: 14 November 2007/Accepted: 24 May 2008/Published online: 25 June 2008

(C) Springer Science+Business Media B.V. 2008

\begin{abstract}
Inferred temperatures from chironomids preserved in the varved sediment of Lake Silvaplana in the Eastern Swiss Alps were compared with instrumental data obtained from a meteorological station in Sils-Maria, on the shore of Lake Silvaplana, for the time interval 1850-2001. At near-annual resolution, the general patterns of chironomid-inferred temperature changes followed the meteorological record over the last $\sim 150$ years $\left(r_{\text {Pearson }}=0.65, P=0.01\right)$ and $87 \%$ of the inferences had deviations from the instrumental data below the root-mean-square error of prediction (RMSEP). When the inferences were
\end{abstract}

I. Larocque $(\bowtie) \cdot$ M. Grosjean

Oeschger Centre for Climate Change Research and Institute of Geography, University of Bern, Erlachstrasse 9A, 3012 Bern, Switzerland

e-mail: larocque@giub.unibe.ch

I. Larocque

INRS-ETE, 490 De La Couronne, Quebec, QC, Canada

G1K 9A9

\section{O. Heiri}

Palaeoecology, Institute of Environmental Biology, Faculty of Science, Utrecht University, Budapestlaan 4, 3584 CD Utrecht, The Netherlands

C. Bigler

Ecology and Environmental Science, Umeå University, 90187 Umea, Sweden

A. Blass

Sonnenbergstrasse 45, 8032 Zurich, Switzerland compared with a 2-year running mean in the meteorological data, $94 \%$ of the inferences had differences with the instrumental data below the RMSEP, indicating that more than half of the inaccurate inferences may have been due to errors in varve counting. Larger deviations from the instrumental data were also obtained from samples with low percentages of fossil taxa represented in the training set used for temperature reconstruction and/or assemblages with poor fit to temperature. Changes in total phosphorus (TP, as inferred by diatoms) and/or greater precipitation were possible factors affecting the accuracy of the temperature reconstruction. Although these factors might affect the quantitative estimates, obtaining $>80 \%$ accurate temperature inferences suggests that chironomid analysis is a reliable tool for reconstructing mean July air temperature quantitatively over the last $\sim 150$ years in Lake Silvaplana.

Keywords Non-biting midges - Meteorological data $\cdot$ Numerical methods $\cdot$ Dating errors .

Climate change

\section{Introduction}

Chironomids are winged insects in their adult form and pass through four larval stages that thrive in various aquatic environments (e.g. ponds, bogs, lakes, rivers). The head capsule of the chironomid larvae is made of chitin, a substance resistant to degradation, 
thus allowing the larval exoskeletons to be preserved in lake sediments. Because both the winged insect and the larval stages are influenced by temperature (air and water, respectively), they have the potential to be used for reconstructing temperature quantitatively. Numerous transfer functions have been developed to reconstruct both water (e.g. Walker et al. 1997) and air temperature (e.g. Brooks and Birks 2000a; Heiri et al. 2003; Larocque et al. 2001, 2006; Larocque and Bigler 2004; Olander et al. 1999). These transfer functions (i.e. calibration in space) have been successfully applied to reconstruct Late-glacial and Holocene climatic changes (e.g. Brooks and Birks 2000b; Caseldine et al. 2003; Heiri and Millet 2005; Langdon et al. 2004, Larocque and Hall 2004; Palmer et al. 2002), although the Holocene epoch sometimes poses problems due to the absence of modern analogues, or factors other than climate having a stronger effect on chironomid assemblages, leading to inaccurate temperature inferences (Brooks 2006; Velle et al. 2005a, b). Critical reviews of the use of chironomids for temperature reconstruction in Europe and in North America can be found in Brooks (2006) and Walker and Cwynar (2006). These reviews clearly indicate that the method has had successes and failures.

Even though chironomids have been successfully applied as temperature indicators for Late-glacial and Holocene times, very few attempts have been made to compare inferences with meteorological observations during the past few centuries. A first validation of the transfer function technique showed that chironomidinferred temperatures compare reasonably well to meteorological data over the last century in northern Sweden (Larocque and Hall 2003). Although these results were promising, other validations are required to support the idea that chironomids can be used to infer climate effectively, and these validations should be made in a wide range of lake types and regions. Here, another attempt at validation is made in Lake Silvaplana, a large $\left(2.7 \mathrm{~km}^{2}\right)$, deep $\left(\mathrm{Z}_{\max }=77 \mathrm{~m}\right)$ lake with varved sediments, located in the eastern Swiss Alps. Although minor errors in dating can be introduced during varve counting, the possibility of comparing inferences at near-annual resolution is unique. This lake is also well suited for such a comparison since a meteorological station is located on its shore, which permits direct comparison between the instrumental data and the chironomid- based inferences. This specific setting allows us to test the hypothesis that chironomids can adequately reconstruct temperature at very high (near-annual) resolution. Previous studies have demonstrated the sensitivity of this lake-sediment record to climate change and human impact (Blass et al. 2007a, b; Ohlendorf et al. 1997). This second validation of chironomid-based inferences with meteorological measurements, in another geographic area than the previously published results from North Sweden and at high temporal resolution, should demonstrate that chironomids can provide adequate estimates of mean July air temperature through time, or point towards potential problems associated with the approach.

\section{Study site}

Regional setting

Lake Silvaplana $\left(46^{\circ} 26^{\prime} 56^{\prime \prime} \mathrm{N}, 9^{\circ} 47^{\prime} 33^{\prime \prime} \mathrm{E} ; 1,791 \mathrm{~m}\right.$ a.s.l.) is located in the Engadine, a high-elevation valley in the eastern Swiss Alps (Fig. 1). This valley has four connected lakes: Lake Sils, Lake Silvaplana, Lake Champfèr and Lake St. Moritz. The lakes are surrounded by mountains reaching ca. 4,000 m a.s.l. Clastic sedimentation is dominant in the upper lakes (Lake Sils, Silvaplana and Champfèr) (Ariztegui et al. 1996). The climate in the Engadine is more continental and drier than in the Swiss Plateau. Maximum temperatures are recorded in July $\left(10.8^{\circ} \mathrm{C}\right)$ and the minima occur in January $\left(-7.8^{\circ} \mathrm{C}\right)$. Maximum precipitation $(121 \mathrm{~mm})$ is in August while the minimum is usually registered in February $(42 \mathrm{~mm})$. The total amount of precipitation is $978 \mathrm{~mm}$ per year (MeteoSchweiz (http://www.meteoschweiz.ch)). The bedrock in this region consists of granite and gneiss, with local carbonate outcrops (Ohlendorf 1998). The dominant trees are Swiss stone pine (Pinus cembra) and larch (Larix decidua), but spruce (Picea abies) and green alder (Alnus viridis) are also present (Gobet et al. 2003). The tree-line is located at ca. 2,200 $\mathrm{m}$ a.s.l.

Study lake

Lake Silvaplana is $3.1 \mathrm{~km}$ long and $1.4 \mathrm{~km}$ wide. The total surface area is $2.7 \mathrm{~km}^{2}$ (Bosli-Pavoni 1971). Its average depth is $48 \mathrm{~m}$ with the deepest part reaching $77 \mathrm{~m}$. Its water volume is $0.14 \mathrm{~km}^{3}$ and the residence 
Fig. 1 Location map of Lake Silvaplana and nearby Lake Sils, connecting rivers and glaciers. The hydrological stations are indicated by squares. The large gray circles are the two villages: Silvaplana and Sils-Maria. Various extracted from Lake Silvaplana (indicated by small dots) and a sediment trap (indicated by an open square) was installed meteorological and sediment cores were

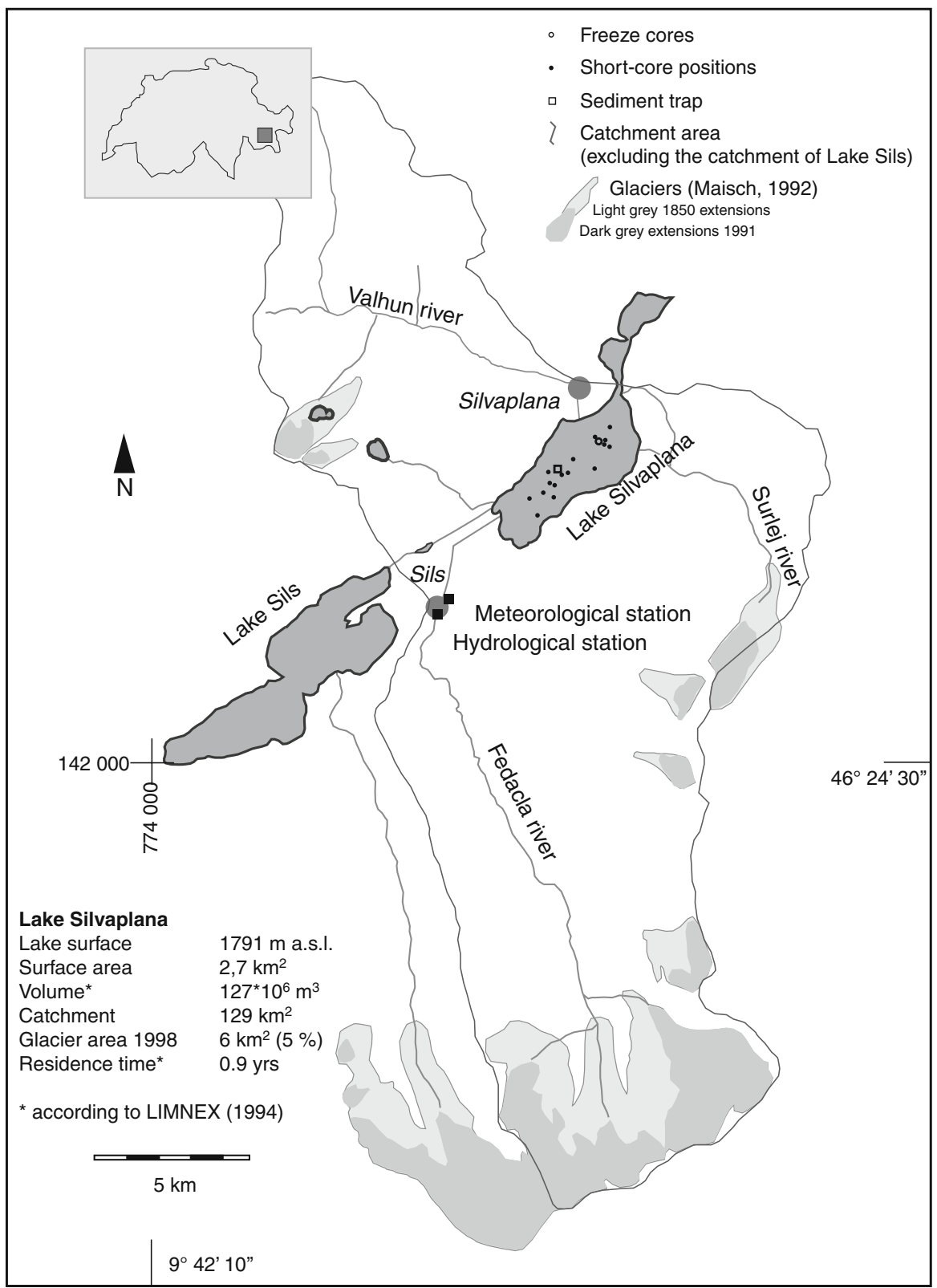

time of lake water is about 250 days. The lake presently does not become anoxic during summer stratification (Blass et al. 2007a). It is oligotrophic $(\mathrm{TP}=8 \mu \mathrm{g} / \mathrm{l})$ and slightly alkaline $(\mathrm{pH}=7.8)$ (Bigler et al. 2006). Eight percent of its catchment area is covered by three small glaciers $(0.89,1.33$ and $2.49 \mathrm{~km}^{2}$ ) south of the lake (Maisch et al. 1999). The glacial melt-water supply is large in summer (Blass et al. 2007b). The most important inflow to Lake Silvaplana is the Fedacla River, which is fed mainly by glacier meltwater and carries a high load of suspended sediment. A second inflow is the Inn River, connecting Lake Silvaplana to Lake Sils. This river contains very little suspended sediment (Blass et al. 2007a).

\section{Methods}

\section{Sampling}

A sediment core was collected in 2002 using a gravity corer, at $77 \mathrm{~m}$ depth. The core had a length of 
$144.5 \mathrm{~cm}$. It was transported complete to the laboratory where it was kept at $4^{\circ} \mathrm{C}$ until analyzed.

\section{Chironomid analysis}

Down to $40 \mathrm{~cm}$, contiguous $0.5-\mathrm{cm}$ samples were used for chironomid analysis. Between 40 and $144.5 \mathrm{~cm}$, every centimetre was analyzed. A solution of $10 \% \mathrm{KOH}$ was added to the samples overnight. The samples were then sieved with a $90-\mu \mathrm{m}$ mesh and the residue was examined under a stereo-zoom microscope at $40 \times$. All the head capsules found were mounted on microscope slides in a solution of Hydromatrix?? The identification followed mainly Wiederholm (1983) and Oliver and Roussel (1983). Specialized keys were used for Tanytarsini (Brooks unpublished, now appearing in Brooks et al. 2007) and Tanypodinae (Rieradevall and Brooks 2001).

\section{Dating}

The chronology of the studied core was established by visual correlation of 19 turbidite and marker horizons (Fig. 2; Bigler et al. 2007) to the well-dated master core (SVP 04-11 and SVP 05-1, Blass et al. 2007a, b). The dating of the master core was based on varve counting of high-resolution digital images, validated by ${ }^{137} \mathrm{Cs}$ and turbidite deposits originating from known, historical flood events (Blass et al. 2007a, b).

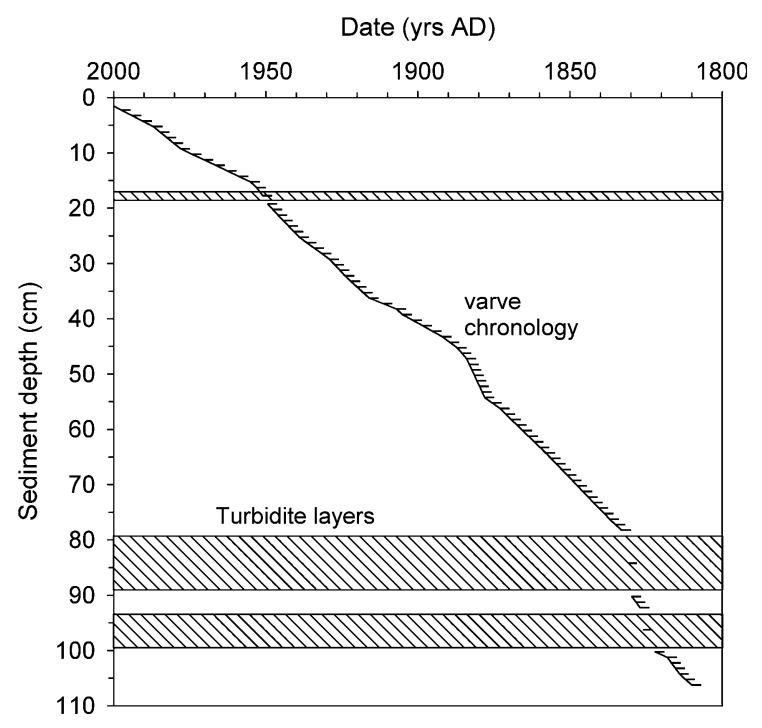

Fig. 2 Depth-age model obtained by varve chronology and correlation between cores (see Methodology for details)
Inference model

A transfer function modified from Heiri et al. (2003), Heiri and Lotter (2005) and Bigler et al. (2006), including 101 lakes (i.e. calibration in space), was used to infer mean July air temperature from fossil chironomid assemblages. Ablabesmyia, Krenopelopia, Guttipelopia, Labrundinia, Thiennemanimyia and Zavrelimyia were included under a single taxonomic group as Pentaneurini. The new transfer function has a leave-one-out, cross-validated coefficient of determination $\left(r^{2}\right)$ of 0.86 , a root-mean-square error of prediction (RMSEP) of $1.5^{\circ} \mathrm{C}$, and a maximum bias of $1.72^{\circ} \mathrm{C}$. The temperature inferences were assessed by (a) the percentage of taxa from the fossil samples, which are found in the training set and (b) the fit of fossil assemblages to temperature (Birks 1998). Fossil samples with less than $80 \%$ of the taxa found in the training set were considered as having poor representation in the modern calibration data. Fossil samples with high residual distances from the first axis of a canonical correspondence analysis (CCA) ordination of the training set assemblages with the fossil samples entered passively are considered to have "poor fit" to temperature (Birks 1998; Larocque and Hall 2004).

\section{Meteorological data}

Monthly averages since 1864 were available from the meteorological station of Sils-Maria located on the shore of Lake Silvaplana. Because the transfer function reconstructs mean July air temperature (Heiri et al. 2003), mean July air temperature of the instrumental data was used for comparison with chironomid inferences. When the chironomid samples represented more than one year, an average of the meteorological data was made using the time represented by the sample. For example, due to low count numbers of chironomid head capsules, samples from 1949 to 1952 were combined, thus an average of the measured mean July air temperatures for this period was calculated.

Statistical analyses

A correspondence analysis (CA) was used to assess the similarity/variability between chironomid assemblages in each sample. The fossil samples were also passively added to a canonical correspondence analysis (CCA) of the training set samples, constrained to 
temperature, to assess the variation of fossil samples through time along the temperature gradient. For both analyses, the data were square-root transformed and the rare species down-weighted. CANOCO version 4.5 (ter Braak and Šmilauer 2002) was used to perform these analyses.

The ZONE program (Juggins 1991) was used to define the zones presented in the stratigraphic diagram. Significant zones were determined using the broken-stick model (Bennett 1996).

A Pearson correlation coefficient was calculated to evaluate the relationship between meteorological data and chironomid-inferred temperatures. The statistical significance of the coefficient was tested using a $t$-test (Scherrer 1984).

\section{Results}

Chironomid assemblages

The total number of head capsules is highly variable; between 15 and 125 head capsules were counted in samples of ca. $30 \mathrm{mg}$ dry weight, the average being 30 head capsules per sample. The chironomid percentage diagram is divided into seven significant zones, using the ZONE program (Fig. 2). The dominant taxa in the core are Orthocladius, Tanytarsus sp., Cricotopus, Corynoneura, Micropsectra insignilobus-type and Psectrocladius sordidellus-group. Some taxa (Heterotanytarsus, Prodiamesa, Zalutschia zalutschicola, Allopsectrocladius, Protanypus and Rheocricotopus) appear only in the first 2-3 zones (1850-1919 AD) all at percentages lower than 15 . Other taxa (Chironomus anthracinus-group, Dicrotendipes, Pseudosmittia and Paraphaenocladius) appear after zone 3 (1919 AD) while Heterotrissocladius brundini-group, Smittia and Stictochironomus are restricted to the uppermost zone (after 1975 AD). Between 1940 and 1947, the assemblages are quite different, which is also indicated by the CA (Fig. 3). These samples are located in the first quadrant while most of the other samples are distributed in the other quadrants. The 1940-1947 samples are dominated by Microtendipes and Procladius while Orthocladius and Cricotopus are present in minor amounts (Fig. 2). These samples also have generally higher numbers of head capsules than the average and are dominated by warm (temperature optimum $>15^{\circ} \mathrm{C}$ ) taxa. Warm taxa are also dominant in the last sample (2001), in 1988, and at the end of zone 5 (1953-1955). The first sample (AD 1850) has higher-than-average warm taxa, but cold taxa (with temperature optimum $<10^{\circ} \mathrm{C}$ ) are still dominant $(48 \%)$. In all other samples, cold taxa percentages are higher than warm taxa percentages.

Samples from the years 1912, 1931, 1992 and $2001 \mathrm{AD}$ seem to have different chironomid assemblages since they are located farther away from the other samples in the CA analysis (Fig. 4). These samples have low numbers of head capsules $(6,10,4$ and 10, respectively) and were pooled with adjacent samples for temperature reconstruction.

Littoral taxa generally dominate the chironomid assemblages, composing on average $50 \%$ of the assemblages. Profundal taxa are also well represented (average of 27\%). Rheophilous taxa are sporadically abundant (up to $30 \%$ in one sample), but have percentages generally lower than $6 \%$.

Comparison with meteorological data

To infer temperature, samples with less than 30 head capsules were grouped with adjacent levels. Although 50 head capsules is usually used as a minimum count for chironomid analysis in lakes with a high chironomid abundance (Heiri and Lotter 2001; Larocque 2001), 30 head capsules can still provide adequate inferences (Heiri and Lotter 2001). This merging of samples decreases the resolution to 2 years (1990/1989, 1970/1969, 1947/1946, 1937/ 1936, 1888/1887), 3 years $(1987-1985,1982-1980$, 1892-1890) and 4 years (1952-1949, 1899-1896) for some periods, although most samples still have annual resolution. The CCA (Fig. 5) suggests that 1931 should have had one of the warmest mean July air temperatures, while 1948 and 1954 should have had the coldest mean July air temperatures. Looking at the meteorological data, the mean July temperature in 1931 was indeed one of the warmest $\left(12.1^{\circ} \mathrm{C}\right)$ while the years 1948 and 1954 had cold mean July air temperatures $\left(7.3\right.$ and $8.5^{\circ} \mathrm{C}$, respectively). Year 1983 shows the warmest recorded temperature in July $\left(13.7^{\circ} \mathrm{C}\right)$ and the sample is located at the warmest end of the temperature gradient. These results suggest that chironomid assemblages have reacted to summer temperature and/or associated limnological changes during the studied time interval. 


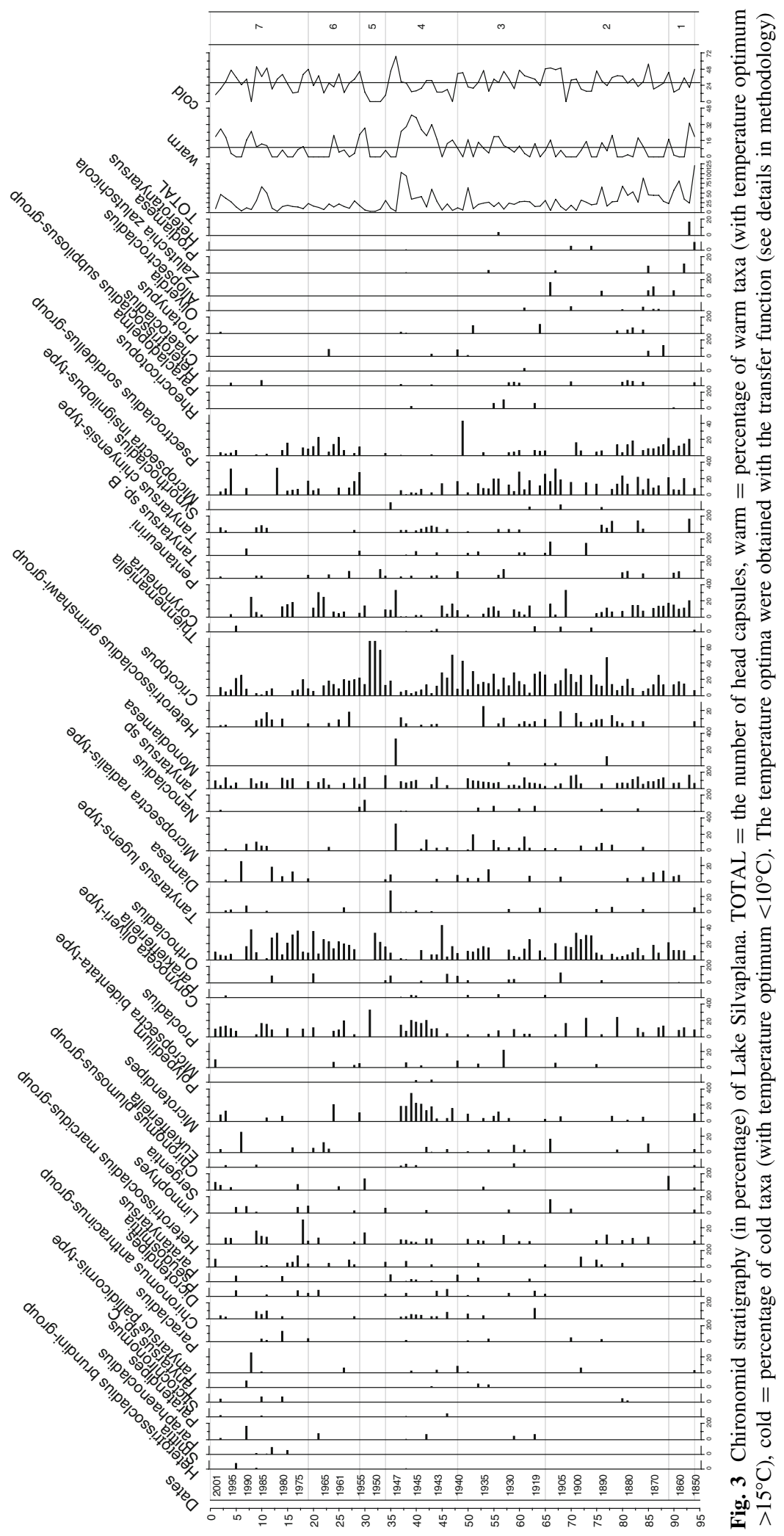




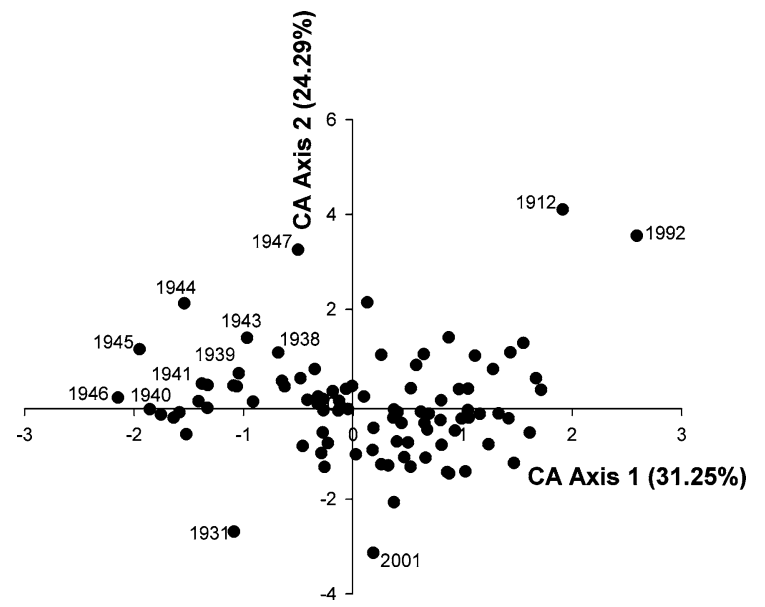

Fig. 4 Correspondence analysis. The numbers in the graph are the years $\mathrm{AD}$ of the samples. The variance explained by each axis is in brackets

Looking at the inferences compared with the meteorological data (Fig. 6), the general pattern of temperature change is effectively recorded by chironomids. At near-annual resolution (Fig. 6a), the inferences are reasonably close to the measured mean July air temperature and the temperature patterns are mostly recorded faithfully. The Pearson correlation coefficient between measured and inferred values is 0.65 and it is statistically significant at $P=0.01$. Due to possible varve-counting errors, a 2-year running mean in the meteorological data was used to compare with the reconstructed temperature (Fig. 6b) and to determine the general pattern of temperature changes through time. Between 1850 and 1930, the patterns are similar and the temperature differences between inferred and measured temperatures are low. After 1935, the differences between the inferences and the measured temperatures become larger, although the general patterns of temperature changes mainly agree. The only major divergence occurs between 1973 and 1979, when the measured temperatures are below average, but chironomid-based inferences are relatively high. The relationship between inferred and measured temperatures is closer to the 1:1 line before 1935 than afterwards, also indicating larger differences between the inferred and the measured temperatures after 1935.

Considering the data at near-annual resolution, nine of the 69 inferences (13\%) have absolute differences in temperature with the instrumental data higher than the RMSEP (Fig. 7a). Of those, two have

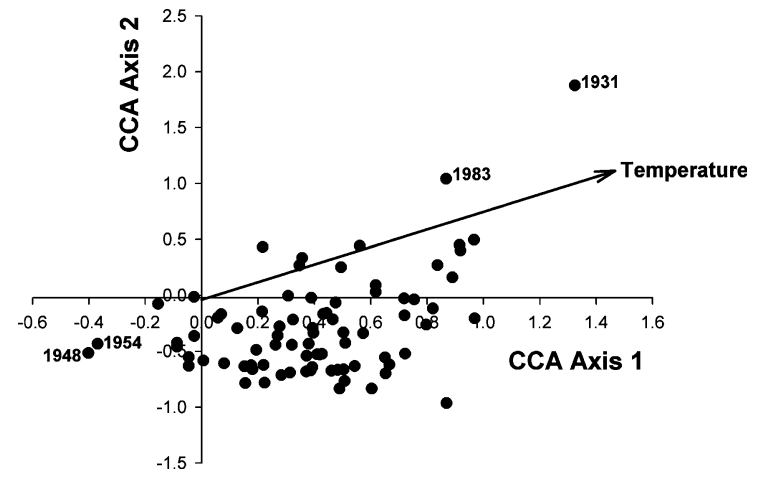

Fig. 5 Canonical correspondence analysis of the fossil samples passively added in the CCA analysis of the training set samples, constrained to temperature. Here, only the fossil samples are presented and the temperature vector. The numbers are the years $\mathrm{AD}$ of the samples

poor fit to temperature and four have both a poor fit to temperature and less than $80 \%$ of their taxa found in the training set. Forty-eight out of the 69 inferences $(78 \%)$ have differences between the instrumental data and the inferences $\leq 1{ }^{\circ} \mathrm{C}$, and 36 out of $69(52 \%)$ have differences $\leq 0.5^{\circ} \mathrm{C}$. The average temperature difference between the instrumental data and the inferences is $0.7^{\circ} \mathrm{C}$. To account for possible errors in varve counting, the inferences were also compared with a 2-year running mean of the meteorological data (Fig. 6b). Four of the 69 inferences $(6 \%$ ) have differences above the RMSEP, 59 (85\%) have differences $<1^{\circ} \mathrm{C}$ and 41 (59\%) have differences $<0.5^{\circ} \mathrm{C}$. These results suggest that some of the larger errors in the near-annual resolution might be due to varve counting errors.

\section{Discussion}

Palaeocology of Lake Silvaplana

Few studies using chironomids as climate indicators have been made in varved lakes. One of the factors allowing for varve preservation in a lake is the lack of bioturbation. Since many chironomid taxa live in tubes in or on the sediment, their presence usually disturbs the varve layering. In Lake Silvaplana, the varves were preserved, even with the presence of chironomids. The most abundant groups of chironomids found in the sediment core (e.g. Cricotopus, Orthocladius, Tanytasus sp.) are littoral, i.e. taxa 

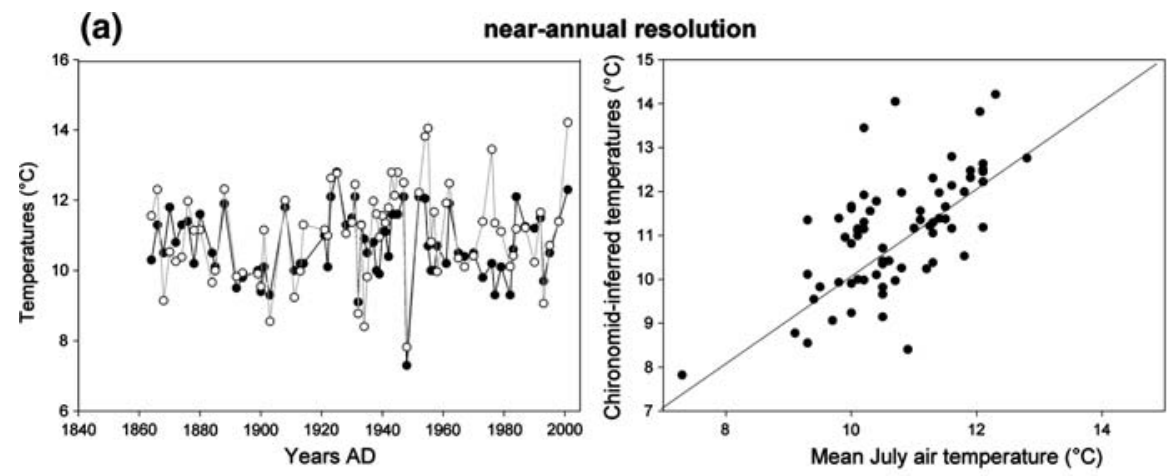

(b)

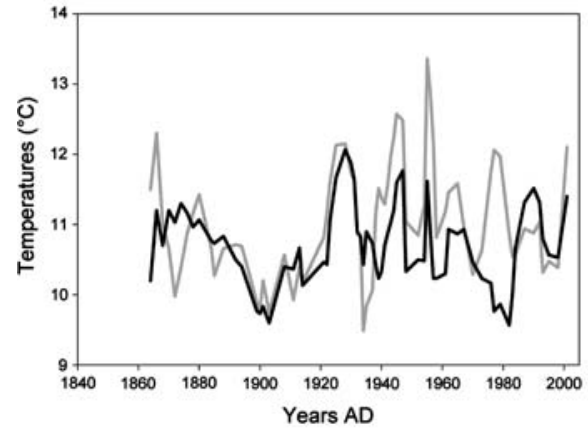

Fig. 6 Temperature inferences (mean July air temperature) obtained with chironomids compared with the instrumental data at (a) near-annual resolution. The left panel shows the general pattern of temperature changes as inferred from chironomids (empty circles) and the instrumental data (black circles). The right panel is the relationship between inferences and instrumental data. The line is the 1:1 relationship (b) with running means. On the left panel, the gray line is a 2-point

known to live in the shallower part of lakes, thus preserving the varves at the sampling point. Profundal taxa (e.g. Heterotrissocladius sp., Sergentia, Procladius, Micropsectra sp.), which could perturb the sediment, also are present, and on average they represent $25 \%$ of the assemblages. Generally, the number of head capsules found in each sample was very low (average of 30 head capsules per 15-30 g of dry sediment) suggesting that the abundance of chironomids at the sampling site was very low. Such low numbers and the dominance of littoral taxa are probably the factors explaining why varves were preserved at Lake Silvaplana.

Lakes as deep as Lake Silvaplana (77 m) are rarely used for climate reconstruction. In such deep lakes, it is expected that profundal taxa will be less affected by climatic change than littoral taxa because the water temperature in deeper parts of the lake remains more or less constant. Here, two of the most abundant 2-year means

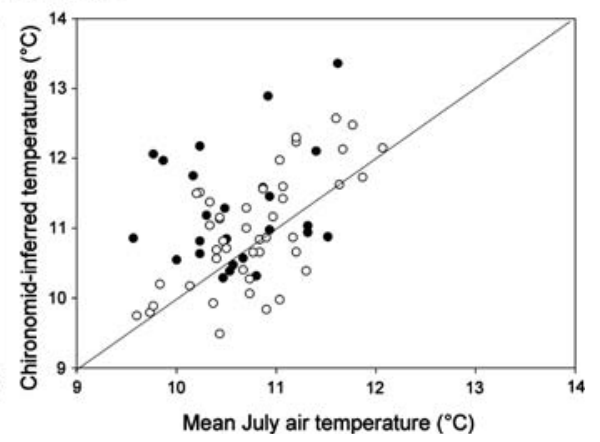

running mean in the temperature inferences while the black line is a 2-year running mean in the instrumental data. The horizontal line is the climate normal (average mean July air temperature between 1960 and 1990). The right panel is the relationship between inferences and instrumental data. The empty circles represent the samples before 1950 and the black circles represent the samples after 1950. The line is the 1:1 relationship

profundal taxa are Micropsectra insignilobus-type and Procladius. Micropsectra insignilobus-type is a taxon associated with cold climate while Procladius is an intermediate/warm taxon. Their respective percentages decrease and increase during zones 4 and 5 (1940-1950) when the climate is generally warm over Europe (Böhm et al. 2001; Casty et al. 2005). These results suggest that profundal taxa can also be affected by variations in climate at Lake Silvaplana, although major changes in climate are recorded mainly by the dominating littoral taxa.

Temperature reconstruction

\section{Pattern of temperature reconstruction}

The pattern of temperature changes recorded using chironomids compares quite well with the meteorological data, especially before 1935 when the 


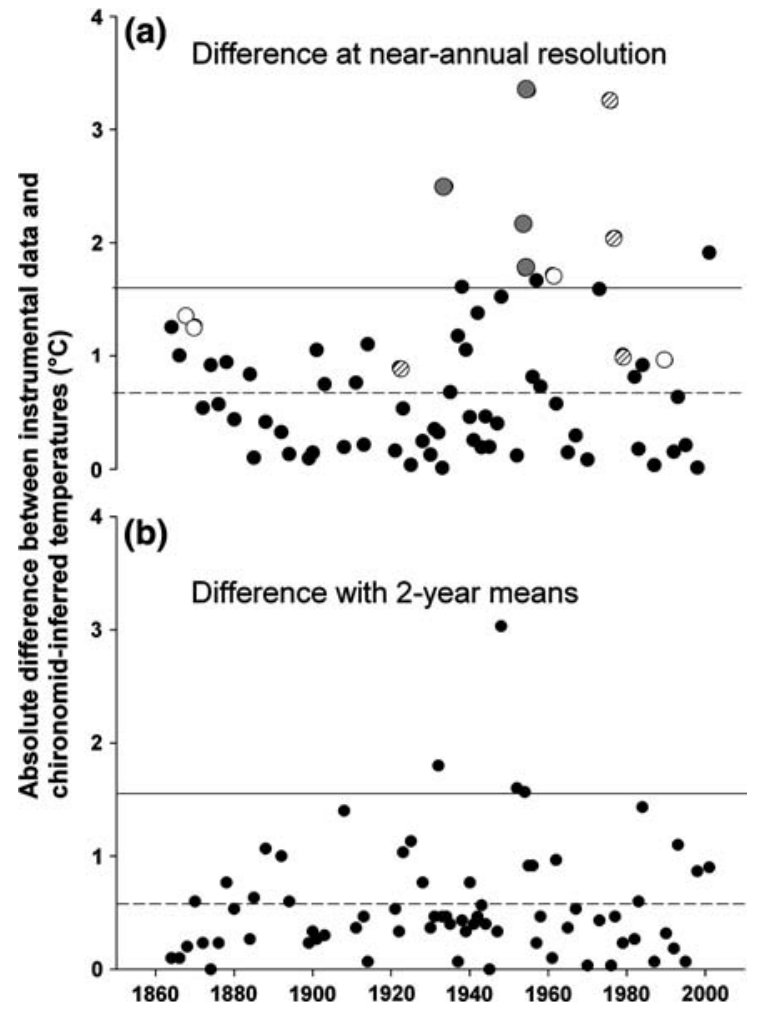

Fig. 7 Absolute differences between the instrumental data and the chironomid-inferred temperatures (in ${ }^{\circ} \mathrm{C}$ ) (a) at near-annual resolution. The white dots indicate samples with less than $80 \%$ of the fossil taxa present in the training set, the lined dots indicate samples with poor fit to temperature and the gray dots indicate samples with poor fit to temperature and with less than $80 \%$ of the fossil taxa present in the training set (b) compared with a 2-year running mean in the instrumental data. The horizontal line is the RMSEP $\left(1.5^{\circ} \mathrm{C}\right)$ and the dotted lines are the average of all differences $\left(0.7^{\circ} \mathrm{C}\right.$ at near-annual resolution, $0.5^{\circ} \mathrm{C}$ with the 2 -year running mean)

differences between the inferences and the instrumental data are lower. Similar patterns of temperature changes were shown in the mean summer (MaySeptember) temperatures: slightly above average temperatures between 1860 and 1880, below average between 1880 and 1920, higher between 1920 and 1930, a decreasing trend between 1930 and 1940, and temperatures increased between 1930 and 1940 (Ohlendorf et al. 1997; Blass et al. 2007a). The same patterns in annual temperature over Europe were described by analyzing instrumental data (Böhm et al. 2001; Casty et al. 2005).

After 1950, there was a higher (but mostly within the RMSEP) deviation between chironomid-based temperature inferences and the instrumental data. Various factors other than climate can affect the chironomid assemblages. It has been shown that chironomid assemblages can be influenced, for example, by oxygen availability (Quinlan and Smol 2001), nutrient (e.g. TP) availability (Lotter et al. 1998), and lake depth (Korhola et al. 2000). In Lake Silvaplana, a diatom-inferred TP reconstruction (DITP) (Bigler et al. 2007) was compared with changes in chironomid assemblages. Bigler et al. (2007) and Blass et al. (2007a) showed that eutrophication (TP as inferred from diatoms and biogenic silica) increased at Lake Silvaplana due to increased human activity in the lake catchment. The relationship between DI-TP and the DCA axis-1 scores in the chironomid assemblages (Fig. 8) is weak, but slightly stronger after $1950\left(r^{2}=0.3, P=0.01\right)$ than between 1864 and $1949\left(r^{2}=0.08\right)$, suggesting that TP had more influence on chironomid assemblages after 1950. TP is a factor influencing the distribution of chironomids in Danish (Brodersen and Lindegaard 1999) and Swiss (Lotter et al. 1998) lakes and the increase of TP might decrease the sensitivity of chironomids to temperature. However, the general pattern of temperature change is still correctly recorded at Lake Silvaplana, suggesting that climate is still the major factor influencing the chironomids, except for the years between 1973 and 1979. During that period, the chironomids led to temperature inferences above the climate normal, while the mean July air temperatures were below the 1960-1990 climate normal. Drastic changes in the diatom composition (large decrease of Cyclotella cyclopuncta and major increase of Stephanodiscus parvus) occurred between ca. 1965 and 1980 (Bigler et al. 2007). DI-TP increased steadily during this period, with major increases $(>30 \mu \mathrm{g} / \mathrm{l})$ at the end of the 1970s. Between 1972 and 1980, the DI-TP was twice the value of $14 \mu \mathrm{g} / \mathrm{l}$ measured in 2002 (Bigler et al. 2007). A sewage treatment plant was established in 1972 in Sils-Maria, on the shore of the lake and a general improvement of waste water management started in the 1970s, gradually decreasing the export of nutrients into the Engadine lakes (Blass et al. 2007a). It is thus possible that the doubling of TP had an impact on chironomid assemblages in Lake Silvaplana, leading to inaccurate mean July temperature inferences, but as soon as TP started to decrease (after the 1980s), the relationship between 
Fig. 8 TP inferred by diatoms and DCA axis-1 scores of the chironomid assemblages

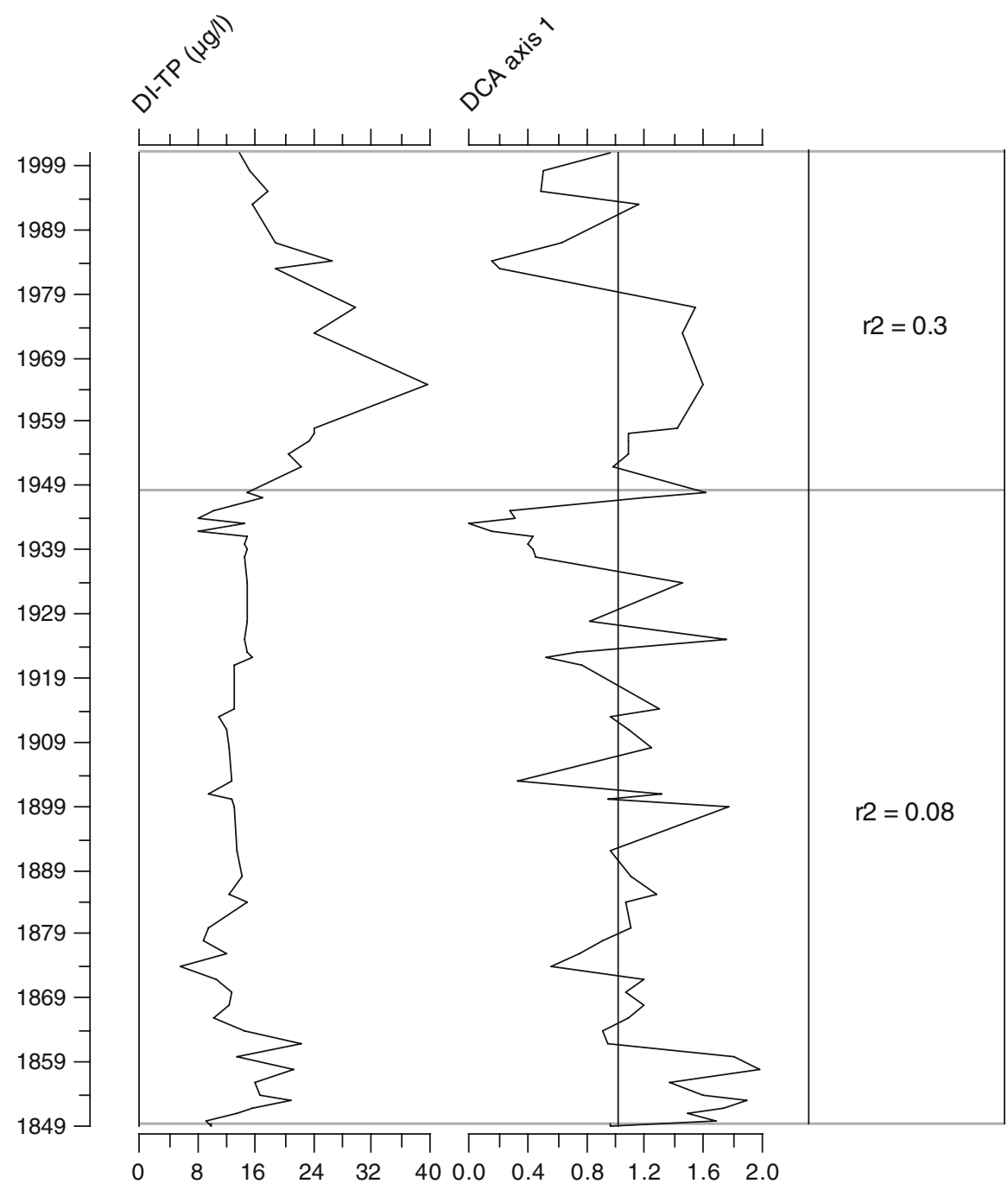

the chironomids and climate became stronger again, leading to accurate (within the RMSEP) inferences.

\section{Performance of the inference model}

When a near-annual comparison is made between the chironomid-inferred temperatures and the instrumental data, most inferences (87\%) display differences from the measured mean July air temperatures below the RMSEP $\left(1.5^{\circ} \mathrm{C}\right)$ and $78 \%$ have less than $1{ }^{\circ} \mathrm{C}$ difference with the measured mean July air temperature. This indicates that in general, chironomids recorded climate reliably within these error margins over the last 150 years, despite possible eutrophication (TP) effects. Similar results were obtained in northern Sweden where, in a comparison of chironomid-inferred temperatures and instrumental data, $89 \%$ of the inferences were below the RMSEP $\left(1.13^{\circ} \mathrm{C}\right)$ of the applied transfer function (Larocque and Hall 2003). In Lake Silvaplana, most samples with high differences between inferences and instrumental data have assemblages with less than $80 \%$ of the taxa represented in the training set and/or with a poor fit to temperature. Factors leading to these inaccurate temperature reconstructions are hard to pinpoint, but uncertainties in varve counting contribute substantially to reconstruction errors at very high temporal resolution, especially when warm and cold mean July air temperature are recorded in subsequent years. When attempting to correct for the possible errors in varve counting by using a 2 -year running mean in the meteorological data, the percentages of 
accurate (i.e. lower than the RMSEP) inferences increases to $94 \%$. The number of inferences with differences from the instrumental data $<1$ and $<0.5^{\circ} \mathrm{C}$ increase sharply as well (85\% and 59\%, respectively). These results suggest that $7 \%$ of the samples may have a residual higher than the RMSEP due to errors in dating, but other factors could have influenced the assemblages in 1948, 1952, 1954-1955 and 2001, which still had differences higher than the RMSEP. Measured precipitation and DI-TP are available at Lake Silvaplana, and their effect on chironomid assemblages was assessed. Higher than average annual precipitation was recorded in 2001, 19541955 and 1948 (Meteo Schweiz). Samples representing these years are located in a similar area of the CCA analysis (Fig. 9) and their assemblages are composed of taxa with species primarily found in running waters (Diamesa, Eukiefferiella, Brillia, Parametriocnemus, Parasmittia), or taxa that could originate from running waters (Cricotopus, Micropsectra) (Oliver and Roussel 1983) or inhabiting the wave zone of the lake. These results suggest that higher precipitation leads to an increase of rheophilic taxa. Since such assemblages are poorly represented in the training set, this may be another source of error leading to inaccurate inferences.

Four samples (1870, 1938, 1942 and 1973) also have larger than $1{ }^{\circ} \mathrm{C}$ differences, but these years did not have higher-than-average precipitation. Year 1973 was the year following the installation of the sewage system, and this new installation might have created a change in the chironomid assemblages by suddenly changing the TP. A rise in TP concentration around 1870 was inferred from diatoms (up to $20 \mu \mathrm{g}$ / 1), while TP decreased to less than $10 \mu \mathrm{g} / \mathrm{l}$ around 1938-1942 (Bigler et al. 2007), suggesting again, that TP might have been an important factor affecting the chironomid assemblages, as was previously shown by Brodersen and Lindegaard (1999) and Lotter et al. (1998). This is another example showing that multiproxy analysis is important to better understand the aquatic system and possible factors influencing organism-based reconstructions.

\section{Number of head capsules}

Before reconstructing mean July air temperature, samples with less than 30 head capsules were grouped together. This limit of 30 head capsules

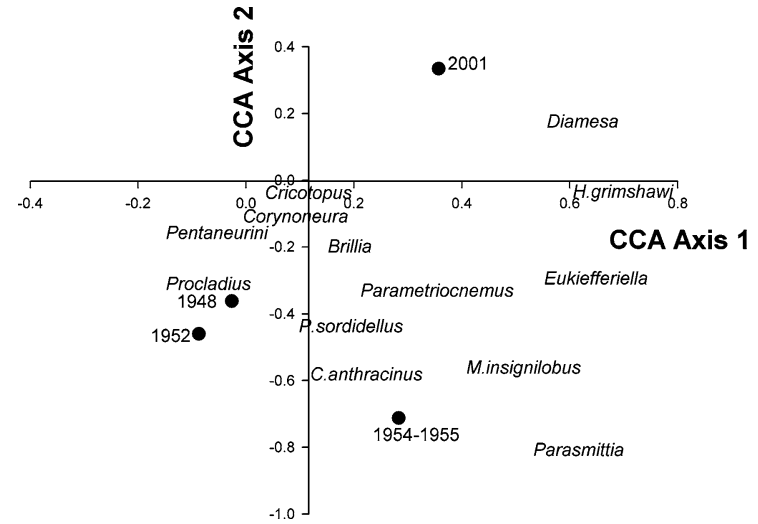

Fig. 9 Canonical correspondence analysis of samples associated with higher-than-average precipitation and the associated taxa found in those samples

was chosen (a) because it is the average number of head capsules found in all samples and (b) because Heiri and Lotter (2001) showed that using only 30 head capsules does not affect the temperature estimates as significantly as using count sums below this threshold, although the authors still recommend a higher minimum count sum. Other studies have shown that the estimates are more accurate when at least 50-75 head capsules are used (Larocque 2001; Velle and Larocque in press). These studies were done with samples in which high numbers $(>150)$ of head capsules were available. The minimum count sum to use for temperature reconstruction has to be adjusted when, throughout a core, the number of head capsules per sample is low. However, since the temperature estimates are based on the temperature optima of each taxon and their abundance (WA-PLS method), the best temperature estimates should be obtained when the right proportions of each taxon are used, independent of the total number of head capsules. By using the average of 30 head capsules found in the samples of Lake Silvaplana, the right proportions for each taxon were possibly still attained in most samples, as is needed for temperature reconstruction. This is suggested by the relationship between the number of head capsules counted and the difference between estimated temperatures and instrumental temperature data (Fig. 10). The highest differences between the estimates and the measured temperatures are obtained when the number of head capsules is below 40 , but only eight of the 50 samples with $<40$ head capsules had differences higher than the RMSEP. These results suggest that, although a 


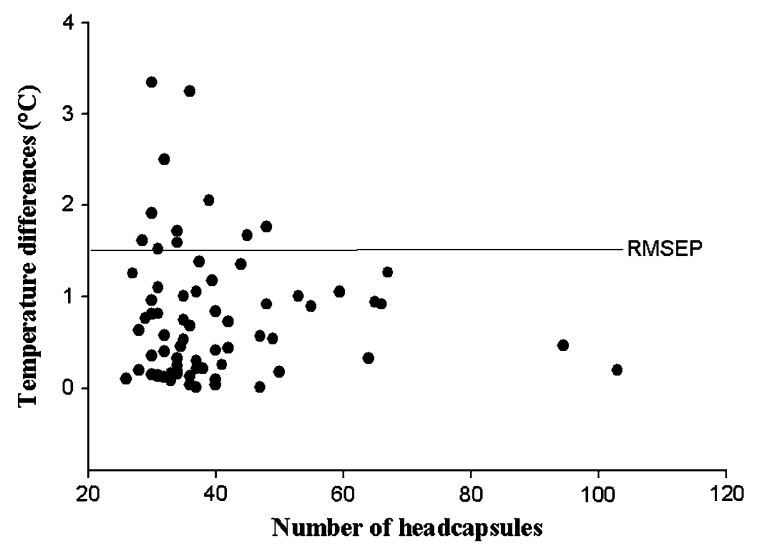

Fig. 10 Relationship between the number of head capsules and the temperature difference between the measured and the estimated mean July air temperature

higher number of head capsules will provide better temperature estimates, it is still possible to use samples with $>30$ head capsules to reconstruct temperature reliably in some lakes. This finding should be further tested elsewhere using sediments with low numbers of head capsules and corresponding instrumental data, enabling a comparison of measured values with chironomid-inferred temperature estimates.

\section{Chironomids and temperature}

Although this study and that of Larocque et al. (2003) indicate that chironomids can reconstruct temperature over the last century reliably, they do not suggest that this is generally the case for all lakes and during all time periods. Many studies show that chironomid-based temperature reconstructions can be contradicted by reconstructions obtained with different proxies during the Holocene (e.g. Heinrichs et al. 2005; Velle et al. 2005a, b). Reasons why the method does or does not perform are still difficult to pinpoint, although major changes in variables other than temperature, such as TP in Lake Silvaplana, or hypolimnetic oxygen (Heiri and Lotter 2003), can lead to shifts in chironomid-inferred temperatures that are unrelated to climate. Characteristics of various study lakes should be examined and the lakes can be evaluated with respect to their ability to yield good or poor climate reconstructions. This should help us learn which lakes are suitable for chironomid-based temperature reconstruction. At present, however, there are still too few studied lakes to determine what factors explain the success or failure of the method in a given geographic region. Here we showed that a large deep lake such as Lake Silvaplana has the potential to provide reliable temperature reconstructions using chironomids, but the absence of a larger number of climate reconstructions in such large, deep lakes prevents us from generalizing the results obtained.

\section{Conclusions}

This paper presents the first quantitative climate reconstruction using chironomids preserved in the sediment of a varved lake in Switzerland. The nearly annually resolved climate reconstruction was compared with instrumental data from Sils-Maria, on the shore of the studied lake. Results indicate that chironomids are accurate quantitative indicators of mean July air temperature because (a) they reflect the temperature changes measured by instrumental data ( $r_{\text {Pearson }}=0.65, P=0.01$ ), and (b) most of the inferences $(94 \%)$ are below the RMSEP $\left(1.5^{\circ} \mathrm{C}\right)$, while $89 \%$ of the inferences have deviations from the instrumental data smaller than $1{ }^{\circ} \mathrm{C}$. These results, and those obtained from cores in northern Sweden (Larocque and Hall 2003), suggest that the quantitative reconstructions obtained for the last century are reliable. However, factors other than mean July air temperature (here TP and precipitation) can influence the chironomid assemblages and produce temperature inferences having large deviations $\left(>1^{\circ} \mathrm{C}\right)$ from the instrumental data. Validations should be obtained from different regions and in different types of lakes to be able to generalize the performance of chironomids as quantitative climate proxies.

Acknowledgements This research was made possible with support from NCCR-Climate and the EU project "MILLENNIUM-European climate of the last millennium (Contract No.: 017008-2). We thank Lucien von Gunten and Florencia Oberli for technical support. We would also like to thank Mark Brenner and two anonymous reviewers for their most useful comments on this manuscript.

\section{References}

Ariztegui D, Farrimond P, McKenzie JA (1996) Compositional variations in sedimentary lacustrine organic matter and their implications for high alpine Holocene environmental 
changes: Lake St-Moritz, Switzerland. Org Geochem 24:453-461 doi:10.1016/0146-6380(96)00046-0

Bennett KD (1996) Determination of the number of zones in a biostratigraphical sequence. New Phytol 132:155-170 doi:10.1111/j.1469-8137.1996.tb04521.x

Bigler C, Heiri O, Krskova R, Lotter AF, Sturm M (2006) Distribution of diatoms, chironomids and cladocera in surface sediments of thirty mountain lakes in south-eastern Switzerland. Aquat Sci 68:154-171 doi:10.1007/s00027006-0813-x

Bigler C, von Gunten L, Lotter AF, Hausmann S, Blass A, Ohlendorf C et al (2007) Quantifying human-induced eutrophication in Swiss mountain lakes since AD 1800 using diatoms. Holocene 17:1141-1154 doi:10.1177/0959 683607082555

Birks HJB (1998) Numerical tools in paleolimnology-progress, potentialities, and problems. J Paleolimnol 20:307322 doi:10.1023/A:1008038808690

Blass A, Bigler C, Grosjean M, Sturm M (2007a) Decadalscale autumn temperature reconstruction back to A.D. 1580 inferred from varved lake sediments of Lake Silvaplana (south-eastern Swiss Alps). Quat Res 68:184-195 doi:10.1016/j.yqres.2007.05.004

Blass A, Grosjean M, Troxler A, Sturm M (2007b) How stable are 20th century calibration models? A high-resolution summer temperature reconstruction for the eastern Swiss Alps back to A.D. 1580 derived from proglacial varved sediments. Holocene 17:51-63 doi:10.1177/095968360 7073278

Böhm R, Auer I, Brunetti M, Maugeri M, Nanni T, Schöner W (2001) Regional temperature variability in the European Alps: 1760-1998 from homogenized instrumental time series. Int J Climatol 21:1779-1801. doi:10.1002/joc.689

Bosli-Pavoni M (1971) Ergebnisse der limnologischen Untersuchungen der Oberengadiber Seen. Z Hydrologie 33:368-409

Brodersen KP, Lindegaard C (1999) Classification, assessment and trophic reconstruction of Danish lakes using chironomids. Freshw Biol 42:143-157 doi:10.1046/j.1365-2427. 1999.00457.x

Brooks SJ (2006) Fossil midges (Diptera: Chironomidae) as palaeoclimatic indicators for the Eurasian region. Quat Sci Rev 25:1894-1910. doi:10.1016/j.quascirev.2005.03.021

Brooks SJ, Birks HJB (2000a) Chironomid-inferred late-glacial and early-Holocene mean July air temperatures for Kråkenes Lake, western Norway. J Paleolimnol 23:77-89. doi:10.1023/A:1008044211484

Brooks SJ, Birks HJB (2000b) Chironomid-inferred Late-glacial air temperatures at Whitrig Bog, southeast Scotland. J Quat Sci 15:759-764. doi:10.1002/1099-1417(200012)15:8<75 9::AID-JQS590>3.0.CO;2-V

Brooks SJ, Langdon PG, Heiri O (2007) The identification and use of Palaearctic Chironomidae larvae in palaeoecology. QRA Technical Guide No. 10, Quaternary Research Association, $276 \mathrm{pp}$

Caseldine C, Geirsdottir A, Langdon P (2003) Efstadalsvatna multi-proxy study of a Holocene lacustrine sequence from NW Iceland. J Paleolimnol 30:55-73 doi:10.1023/A: 1024781918181

Casty C, Wanner H, Luterbacher J, Esper J, Böhm R (2005) Temperature and precipitation variability in the European
Alps since 1500. Int J Climatol 25:1855-1880. doi: 10.1002/joc. 1216

Gobet E, Tinner W, Hochuli PA, van Leeuwen JFN, Ammann B (2003) Middle to Late Holocene vegetation history of the Upper Engadine (Swiss Alps): the role of man and fire. Veg Hist Archaeobot 12:143-163 doi:10.1007/s00334003-0017-4

Heinrichs M, Barnekow L, Rosenberg S (2005) A comparison of chironomid biostratigraphy from Lake Vuolep Njakajaure with vegetation, lake-level, and climate changes in Abisko National Park, Sweden. J Paleolimnol 36:119-131 doi:10.1007/s10933-006-0010-x

Heiri O, Lotter AF (2001) Effect of low count sums on quantitative environmental reconstructions: an example using subfossil chironomids. J Paleolimnol 26:343-350. doi:10.1023/A:1017568913302

Heiri O, Lotter AF (2003) 9000 years of chironomid assemblage dynamics in an Alpine lake: long-term trends, sensitivity to disturbance, and resilience of the fauna. J Paleolimnol 30:273-289. doi:10.1023/A:10260369 30059

Heiri O, Lotter AF (2005) Holocene and Lateglacial summer temperature reconstruction in the Swiss Alps based on fossil assemblages of aquatic organisms: a review. Boreas 34:506-516. doi:10.1080/03009480500231229

Heiri O, Millet L (2005) Reconstruction of Late Glacial summer temperatures from chironomid assemblages in Lac Lautrey (France). J Quat Sci 20:33-44. doi:10.1002/jqs.895

Heiri O, Lotter AF, Hausmann S, Kienast F (2003) A chironomid-based Holocene summer air temperature reconstruction from the Swiss Alps. Holocene 13:477-484. doi: 10.1191/0959683603hl640ft

Juggins S (1991) ZONE software, Version 1.2. Newcastle University, Newcastle

Korhola A, Olander H, Blom T (2000) Cladoceran and chironomid assemblages as qualitative indicators of water depth in subarctic Fennoscandian lakes. J Paleolimnol 24:43-54. doi:10.1023/A:1008165732542

Langdon PG, Barber KE, Lomas-Clarke SH (previously Morriss) (2004) Reconstructing climate and environmental change in Northern England through chironomid and pollen analyses: evidence from Talkin Tarn, Cumbria. J Paleolimnol 32:197-213. doi: 10.1023/B:JOPL.00000294 33.85764.a5

Larocque I (2001) How many chironomid head capsules is enough? A statistical approach to determine sample size for paleoclimatic reconstruction. Palaeogeogr Palaeoclimatol Palaeoecol 172:133-142. doi:10.1016/S0031-0182 (01)00278-4

Larocque I, Bigler C (2004) Similarities and discrepancies between chironomid- and diatom-inferred temperature reconstructions through the Holocene at Lake 850, northern Sweden. Quat Int 122:109-121. doi:10.1016/j.quaint. 2004.01.033

Larocque I, Hall RI (2003) Chironomids as quantitative indicators of mean July air temperature: validation by comparison with century-long meteorological records from northern Sweden. J Paleolimnol 29:475-493. doi: 10.1023/A:1024423813384

Larocque I, Hall RI (2004) Holocene temperature estimates and chironomid community composition in the Abisko 
Valley, northern Sweden. Quat Sci Rev 23:2453-2465. doi:10.1016/j.quascirev.2004.04.006

Larocque I, Hall RI, Grahn E (2001) Chironomids as indicators of climate change: a 100-lake training set from a subarctic region of northern Sweden (Lapland). J Paleolimnol 36:307-322. doi:10.1023/A:1017524101783

Larocque I, Pienitz R, Rolland N (2006) Factors influencing the distribution of chironomids in lakes distributed along a latitudinal gradient in northwestern Quebec, Canada. Can J Fish Aquat Sci 63:1286-1297. doi:10.1139/F06-020

Lotter AF, Birks HJB, Hofmann W, Marchetto A (1998) Modern diatom, cladocera, chironomid, and chrysophyte cyst assemblages as quantitative indicators for the reconstruction of past environmental conditions in the Alps. II. Nutrients. J Paleolimnol 19:443-463. doi: 10.1023/A:1007994206432

Maisch M, Wipf A, Denneler B, Battaglia J, Benz C (1999) Die Gletscher der Schweizer Alpen. Schlussbericht NFP 31, Verlag, Zürich, 373 pp

Ohlendorf C (1998) High alpine lake sediments as chronicles for regional glacier and climate history in the Upper Engadine, southeastern Switzerland. Dissertation, ETH, Zürich, $203 \mathrm{pp}$

Ohlendorf C, Niessen F, Weissert H (1997) Glacial varve thickness and 127 years of instrumental climate data: a comparison. Clim Change 36:391-411. doi:10.1023/A: 1005376913455

Olander H, Birks HJB, Korhola A, Blom T (1999) An expanded calibration model for inferring lake water and air temperatures from fossil chironomid assemblages in northern Fennoscandia. Holocene 9:279-294. doi:10.1191/09596 8399677918040

Oliver DR, Roussel ME (1983) The insects and arachnids of Canada, Part II. The genera of larval midges of Canada. Agriculture Canada, Publication 1746, 263 pp

Palmer S, Walker IR, Heinrichs M, Hebda R, Scudder G (2002) Postglacial midge community change and Holocene palaeotemperature reconstructions near treeline, southern
British Columbia (Canada). J Paleolimnol 28:469-490. doi:10.1023/A:1021644122727

Rieradevall M, Brooks SJ (2001) An identification guide to subfossil Tanypodinae larvae based on cephalic setation. J Paleolimnol 25:81-99. doi:10.1023/A:1008185517959

Quinlan R, Smol JP (2001) Chironomid-based inference models for estimating end-of-summer hypolimnetic oxygen from south-central Ontario shield lakes. Freshw Biol 46:1521-1551. doi:10.1046/j.1365-2427.2001.00763.x

Scherrer B (1984) Biostatistique. In: Morin G (ed), Boucherville, Québec, Canada

ter Braak CJF, Šmilauer P (2002) CANOCO Reference manual and CanoDraw for Window User's guide: Software for Canonical Community Ordination (version 4.5). Microcomputer Power, Ithaca, NY, USA, 500 pp

Velle G, Larocque I Exploring the effect of removing taxa smaller than $150 \mu \mathrm{m}$ on temperature reconstruction in cold (mean July/August air temperature $\leq 11^{\circ} \mathrm{C}$ ) lakes. J Paleolimnol (in press)

Velle G, Larsen J, Eide W, Peglar SM, Birks HJB (2005a) Holocene environmental history and climate of Ratasjoen, a low alpine lake in south-central Norway. J Paleolimnol 33:129-153. doi:10.1007/s10933-004-2689-x

Velle G, Brooks SJ, Birks HJB, Willassen E (2005b) Chironomids as a tool for infering Holocene climate: an assessment based on six sites in southern Scandinavia. Quat Sci Rev 24:1429-1462

Walker IR, Cwynar LC (2006) Midges and palaeotemperature reconstruction - the North American experience. Quat Sci Rev 25:1911-1925. doi:10.1016/j.quascirev.2006.01.014

Walker IR, Levesque AJ, Cwynar LC, Lotter AF (1997) An expanded surface-water palaeotemperature inference model for use with fossil midges from eastern Canada. J Paleolimnol 18:165-178. doi:10.1023/A:1007997602935

Wiederholm Y (1983) Chironomidae of the Holartic region, Part 1, Larvae. Entomologica Scandinavia, Supplement 19, 457 pp 